\title{
REFLEXIONES EN TORNO AL ESPACIO DOMÉSTICO: EL CASO DEL RECINTO 353 DEL SITIO LA HuerTA (QuebradA DE Humahuaca, provincia de Jujuy, Argentina) María Andrea Runcio*
}

\section{Resumen}

El trabajo presenta algunas reflexiones en relación al espacio doméstico y la dicotomía espacio público/doméstico a partir del análisis de las evidencias recuperadas en el recinto 353 ubicado en el sector incaico del sitio La Huerta (Quebrada de Humahuaca, provincia de Jujuy, Argentina).

\section{Palabras clave}

Espacio público, espacio doméstico, recinto 353.

\begin{abstract}
The paper presents some thoughts about domestic space and the dichotomy between public space and domestic space; they are based on the analysis of the evidence recovered at enclosure 353 which is located in the Inca sector of La Huerta site (Quebrada de Humahuaca, Jujuy province, Argentina).
\end{abstract}

Keywords

Public space, domestic space, enclosure 353.

* Centro de Investigaciones Precolombinas, Instituto Superior del Profesorado "Dr. Joaquín V. González" (Buenos Aires, Argentina).

Correo electrónico: andrearuncio@hotmail.com 


\section{INTRODUCCIÓN}

En las últimas décadas la disciplina arqueológica ha reconsiderado el rol que el espacio juega en la conformación de los procesos y relaciones sociales.

Algunos autores (Criado Boado 1993; Tilley 1994; Thomas 1996) sostienen que el concepto de espacio usado habitualmente se vincula a significados propios de la modernidad y por lo tanto no puede ser utilizado para estudiar otro tipo de sociedades.

Criado Boado (1993) indica que durante mucho tiempo se ha evitado considerar el espacio como un problema histórico-político y su estudio ha caído bajo categorías deterministas y ecológicas, considerándolo como territorio de dominio y explotación. Esta noción de espacio -sostiene el autor- no es inocente ni accidental, sino que corresponde a la definición del mismo aparecida a partir la Modernidad como condición necesaria para el desarrollo de la revolución industrial y el capitalismo. Por lo tanto, para el estudio de las sociedades pre-capitalistas no deberían utilizarse las categorías y modelos surgidos en un contexto histórico específico -el capitalismo- y que sirven a sus intereses.

La propuesta alternativa a la concepción funcionalista, empírica y moderna del espacio (sensu Criado Boado 1993) postula que el mismo constituye una dimensión activa y significativa que modela la vida de los individuos y sociedades (Ingold 1993; Tilley 1994; Thomas 1996, 2001). De esta manera, las formas espaciales como los lugares, los paisajes y el espacio socialmente construido, juegan un rol activo en la dinámica social produciendo, reproduciendo y modificando algunas acciones, prácticas y significados y encubriendo otros, contribuyendo -de esta forma- a la legitimación del orden social existente.

Entre las diferentes formas de espacios socialmente construidos, el espacio doméstico constituye uno de los más importantes en tanto ámbito primordial de aprendizaje, socialización y producción de los individuos de una comunidad.
En este trabajo se presentará el análisis de las actividades desarrolladas en el recinto 353 del sitio La Huerta (Quebrada de Humahuaca, noroeste de Argentina) y a partir del mismo una reflexión en torno a la concepción del espacio doméstico.

\section{El espacio DOMÉSTICO}

De acuerdo con Hendon (1996) la mayoría de los estudios sobre el espacio doméstico se centran en las actividades que realiza la unidad doméstica. Sin embargo -señala la autora- no es suficiente centrarse en las actividades solamente, de igual importancia es la dimensión simbólica, lo que podría llamarse la "idea" de la unidad doméstica; es decir, lo que la gente hace como miembros de un grupo doméstico y el significado asignado a sus acciones es esencial para entender la dinámica de la misma.

De esta forma, Hendon critica la idea de la unidad doméstica como entidad social indiferenciada y homogénea. Señala que todas las unidades domésticas en una sociedad pueden realizar las mismas tareas básicas e interactuar con el mismo ambiente físico y social pero no necesariamente responden en la misma forma a condiciones externas ni se organizan de manera igual. Aunque los miembros de un grupo doméstico son claramente interdependientes, no son una unidad corporativa en la cual los individuos automáticamente subordinan sus deseos en beneficio del grupo. Tampoco las decisiones se toman a nivel de la unidad doméstica como un todo. El grupo doméstico está conformado por actores sociales diferenciados cuyas acciones e intereses no siempre coinciden.

De acuerdo con la misma autora, la orientación funcional de las investigaciones más corrientes sobre espacio doméstico conducen a caracterizar de antemano las acciones de las unidades domésticas como "domésticas" lo cual es tomado como un conjunto evidente de actividades y relaciones definidas a priori conduciendo a generalizaciones y perdiendo la riqueza de la variabilidad que puede aportar el análisis de casos específicos. Para la autora, es necesario estudiar la unidad doméstica como un espacio 
de relaciones sociales, económicas y simbólicas que interactúa dinámicamente con la sociedad mayor y por lo tanto, considerar al grupo doméstico como un conjunto de actores sociales con capacidad para crear, recrear y transformar las pautas sociales en un contexto específico.

Estas ideas se acercan a los enfoques más recientes enmarcados en las nuevas concepciones de espacio ya mencionadas. Particularmente, el espacio doméstico es considerado como un ámbito de reproducción pero también de negociación del orden social en tanto es el lugar por excelencia donde se realiza el aprendizaje de las pautas sociales y la socialización de los individuos. El espacio doméstico permite reproducir pero también desafiar el orden social y la ideología dominante en tanto, como espacio socialmente construido, configura y es configurado por los miembros de la sociedad.

Finalmente, una propuesta interesante es la formulada por Tilley (1999) quien sostiene que la cultura material en general (incluyendo las casas o viviendas) pueden constituirse en metáforas de los principios del orden social que permiten entender y ordenar el mundo en el que se vive.

\section{La Quebrada de Humahuaca durante los PERIODOS TARDí́ E INCA (900-1536 D.C.)}

La larga ocupación prehistórica de la Quebrada de Humahuaca, ubicada en la provincia de Jujuy en el noroeste de Argentina (Fig. 1), manifiesta cambios en el patrón de asentamiento de los grupos que la habitaron desde el periodo Temprano (300-700 d.C.) hasta el Tardío (900-1430 d.C.). La tendencia observada es el progresivo abandono de las quebradas laterales y tributarias a la de Humahuaca, ocupadas durante los momentos más tempranos, y la concentración de los sitios en la quebrada troncal en los momentos anteriores a la llegada incaica. Las sociedades que habitaron estos sitios en el Tardío (entre ellos La Huerta) constituyen unidades políticas con una organización fragmentada, es decir, grupos que permanecían más o menos independientes entre sí en cuanto a su organización socio-política aunque podían establecer alianzas frente a un objetivo común, dando pie a una incipiente

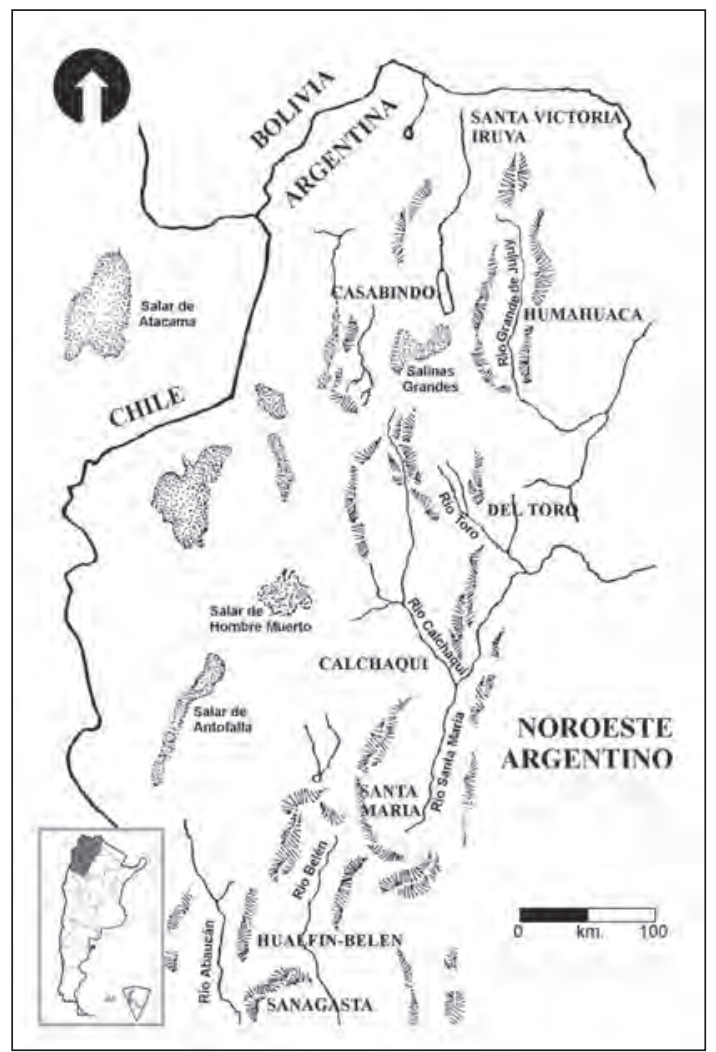

\section{Figura 1: Quebrada de Humahuaca, noroeste de Argentina.}

jerarquización sociopolítica. En principio, a estos grupos se les ha atribuido características de “jefaturas" (Nielsen 1996; Palma 2000) y más recientemente han sido caracterizados como sociedades con una organización comunitaria y descentralizada bajo una autoridad corporativa (Nielsen 2007).

La ocupación incaica de la quebrada (1430. 1536 d.C.) trajo importantes cambios sociales, económicos y políticos en la región, como producto de la incorporación de las sociedades locales al Tawantinsuyu. La ocupación no produjo aparentemente fracturas en la organización general pero impuso una mayor centralización, producto de la dominación política y económica (Palma 1996: 49).

Así, la presencia inca modificó las relaciones socio-políticas existentes alterando, en algunos casos, la funcionalidad de los sitios. Algunos de los asentamientos de importancia durante mo- 
mentos pre-incaicos (Tilcara, La Huerta) experimentaron importantes modificaciones, en tanto grandes complejos arquitectónicos fueron edificados en sectores privilegiados de los mismos, mientras que otros fueron total o parcialmente abandonados (Juella, Los Amarillos). Aparecen, también, sitios inca sin ocupación previa, construidos bajo supervisión estatal y vinculados a la administración (santuarios de altura, postas de enlace, sitios de almacenaje) (Nielsen 2001).

Asimismo, la producción agrícola experimentó un gran incremento como consecuencia de la tecnificación introducida por el estado en los centros productivos pre-incaicos (Coctaca, Rodero), lo que se observa en la ampliación y complejización de las áreas de cultivo y de los sistemas de riego así como la construcción de kollkas (Nielsen 1996).

\section{El sitio La Huerta}

La Huerta (Fig. 2) es uno de los sitios que habría funcionado como centro de importancia sociopolítica durante los periodos Tardío e Inca. Se ubica en la quebrada del mismo nombre a $3 \mathrm{~km}$ al este de la confluencia de ésta con la de $\mathrm{Hu}$ -

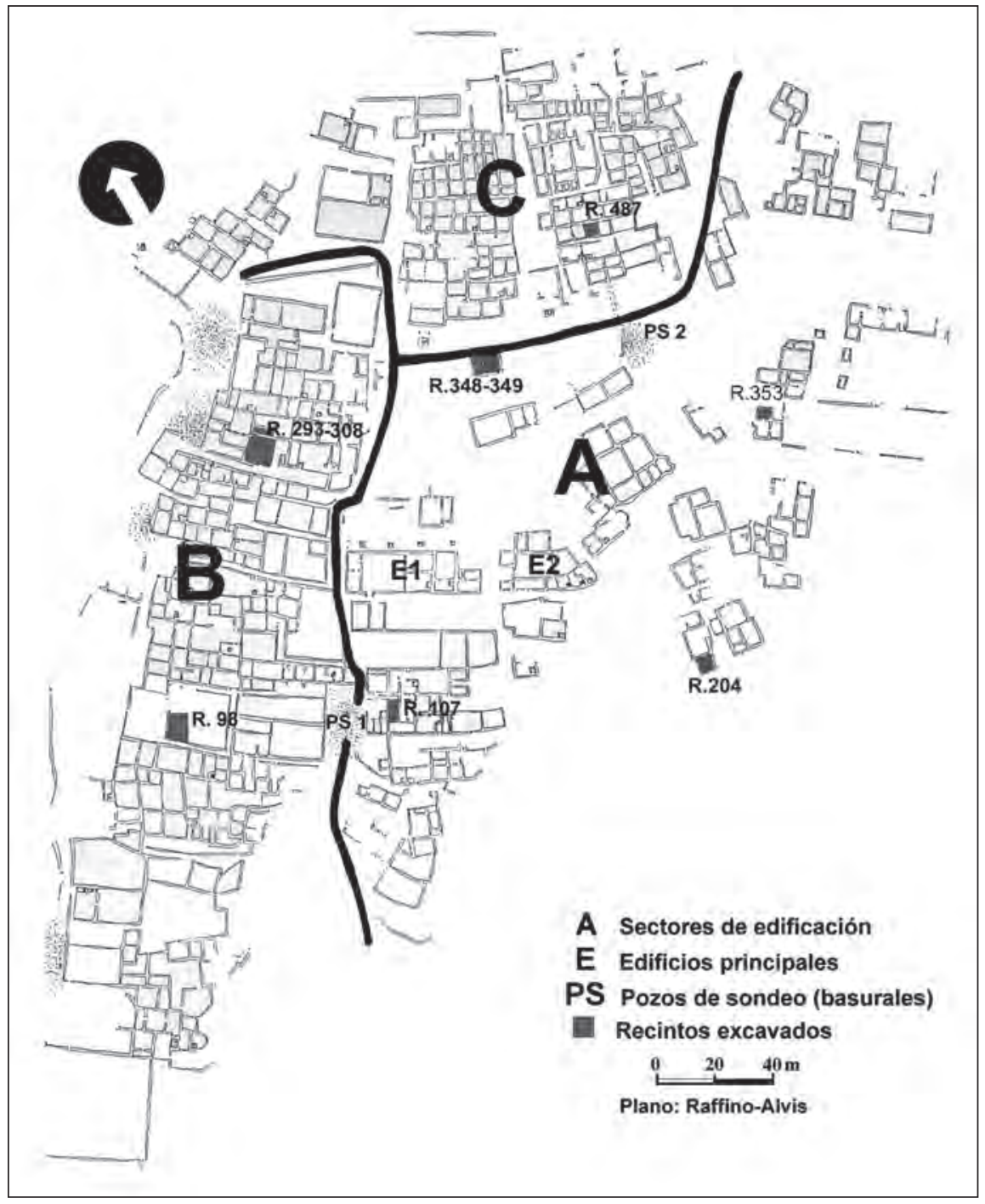

Figura 2: Plano del sitio La Huerta 
mahuaca, ocupando un espolón triangular sobre una ladera del cerro Sisilera.

El sitio toma la forma de un gran agrupamiento semi-urbano, parcialmente planificado, emplazado sobre una elevación natural y con una importante complejidad interna (corrales, vías de circulación, división en sectores). Su trazado es de tipo concentrado, en damero regular en los sectores norte y oeste e irregular en el sector sur y cubre 8,12 Ha (Raffino y Alvis 1993).

Pueden distinguirse tres sectores dentro del sitio (Palma 1996) (Fig. 2):

El sector A, ubicado hacia el sur y el este del sitio, rodea un espacio intencionalmente despejado o plaza. Comprende una serie de recintos de adscripción incaica, entre los que se destacan dos edificios principales. El Edificio 1 (E-1) tiene $640 \mathrm{~m}^{2}$ de superficie y posee claros rasgos arquitectónicos inca (hornacinas, hastial). El otro edificio (E-2) tiene $450 \mathrm{~m}^{2}$ y es más pobre en atributos incaicos, aunque por su ubicación preferencial y la riqueza de sus tumbas (Palma 1993; Raffino, García Montes y Manso 1993), podría tratarse del espacio residencial de las elites.

El sector B, al sur y oeste del sitio, incluye los edificios relacionados con los momentos de ocupación pre-inca que continúan ocupados hasta la conquista hispana. Sería un espacio residencial de grupos no jerarquizados.

El sector C, situado al norte del sitio, está ligado a un episodio constructivo tardío, probablemente contemporáneo a la presencia incaica. Lo constituyen dos grupos de edificios ubicados a ambos lados del camino del Inca, que atraviesa el sitio en sentido SO-NE.

Los recintos corresponden mayoritariamente a los tipos recintos intercomunicados y recintos asociados desiguales. Se hallan articulados en grupos de 2 a 3 formando unidades compuestas y es frecuente que estas asociaciones se produzcan entre recintos de diferentes dimensiones (Raffino y Alvis 1993).

El sitio ofrece alternadamente arquitectura a nivel y subterránea. En relación a la primera,
Raffino y Alvis (1993) han agrupado los recintos en cuatro estratos:

Estrato 1 (19 recintos): son los de superficie más grande (mayores a $150 \mathrm{~m}^{2}$ ), consisten en ámbitos de participación comunitaria o pública, con fácil entrada y salida, conectados con el camino incaico. Pudieron funcionar como corrales de encierro de camélidos, carga y descarga de llamas o para la matanza y trozado de animales.

Estrato 2 (276 recintos): son patios internos o externos a unidades de vivienda donde se desarrollaron múltiples actividades vinculadas al ámbito doméstico (molienda, manufactura de artefactos, cocción de alimentos, etc.). Bajo los pisos de estos recintos se practicaron inhumaciones tanto directas como en cámaras funerarias y urnas. Sus medidas varían entre 25 y $150 \mathrm{~m}^{2}$.

Estrato 3 (239 recintos): con medidas que oscilan entre 10 y $25 \mathrm{~m}^{2}$, consisten en habitaciones de albergue y descanso, potencialmente techadas.

Estrato 4 (80 recintos): menores a $10 \mathrm{~m}^{2}$, cumplieron funciones de cocina y preparación de alimentos, depósitos de herramientas y materias primas. Estuvieron techados y pudieron servir también de albergue nocturno.

Las construcciones subterráneas son de dos tipos: tumbas y depósitos. Las primeras ubicadas dentro de los recintos del estrato 2 , adosadas a los muros o en el interior de los mismos y los segundos ubicados en los faldeos o alineados dentro del gran sector libre de recintos en el área central del sitio.

\section{El Recinto 353}

Se ubica en el sector A del sitio, en una parte sobre-elevada del mismo hacia SE de una cárcava que lo divide en sentido NE-SO (Fig. 2). Se halla inmediatamente asociado a los recintos 354 y 355 (de tamaño similar) comunicándose con este último a través de una abertura que presenta una gran roca rectangular y plana ubi- 
cada hacia el interior del recinto 353 a modo de "puerta". Posee muros simples con piedras sin cantear aunque algunas se presentan ligeramente trabajadas y no se observan accesos desde el exterior (Fig. 3).

Tiene planta rectangular y una superficie de $77,6 \mathrm{~m}^{2}$. Si bien por su superficie correspondería al Estrato 2 definido por Raffino y Alvis (1993) para los recintos del sitio, a diferencia de los grandes patios correspondientes a este estrato, el recinto 353 no presenta estructuras funerarias ni fogones; solo se han detectado dos pequeñas lentes de cenizas.

En la excavación se registró la presencia de cuatro capas correspondiendo la primera a un sedimento arenoso de entre 5 y $7 \mathrm{~cm}$ de espesor, seguida por un sedimento compacto con clastos pequeños, culturalmente fértil, de entre 12 y $18 \mathrm{~cm}$ de espesor. Luego continua un sedimento arcilloso muy compacto color grisáceo que corresponde al piso de ocupación, debajo del cual se halla el pedregullo correspondiente a la capa estéril.
Se observa en el sector SO del recinto un agujero de poste que habría sostenido una techumbre parcial apoyada sobre los muros $\mathrm{O}$ y $\mathrm{S}$. $\mathrm{Al}$ respecto, en esta área se han hallado restos de tirantes de cardón (Trichocereus volcanensis) una cactácea típica de la zona, lo que sostendría esta idea (Fig. 4).

Con respecto a las actividades desarrolladas en el mismo, las evidencias recuperadas indican que fue un espacio donde se realizaron múltiples tareas.

En el sector NO del recinto se han recuperado varios artefactos vinculados a las actividades de molienda, entre ellos: tres metates y seis manos de moler. Se destaca, también en el mismo sector, una gran olla ordinaria de $44 \mathrm{~cm}$ de alto, la cual carece de base y borde y fue hallada enterrada con la boca a la altura del piso. En su interior contenía dos pequeños morteros y una mano de moler. Parece que una vez descartada de su función habitual fue reutilizada como depósito de instrumentos (Fig. 4).

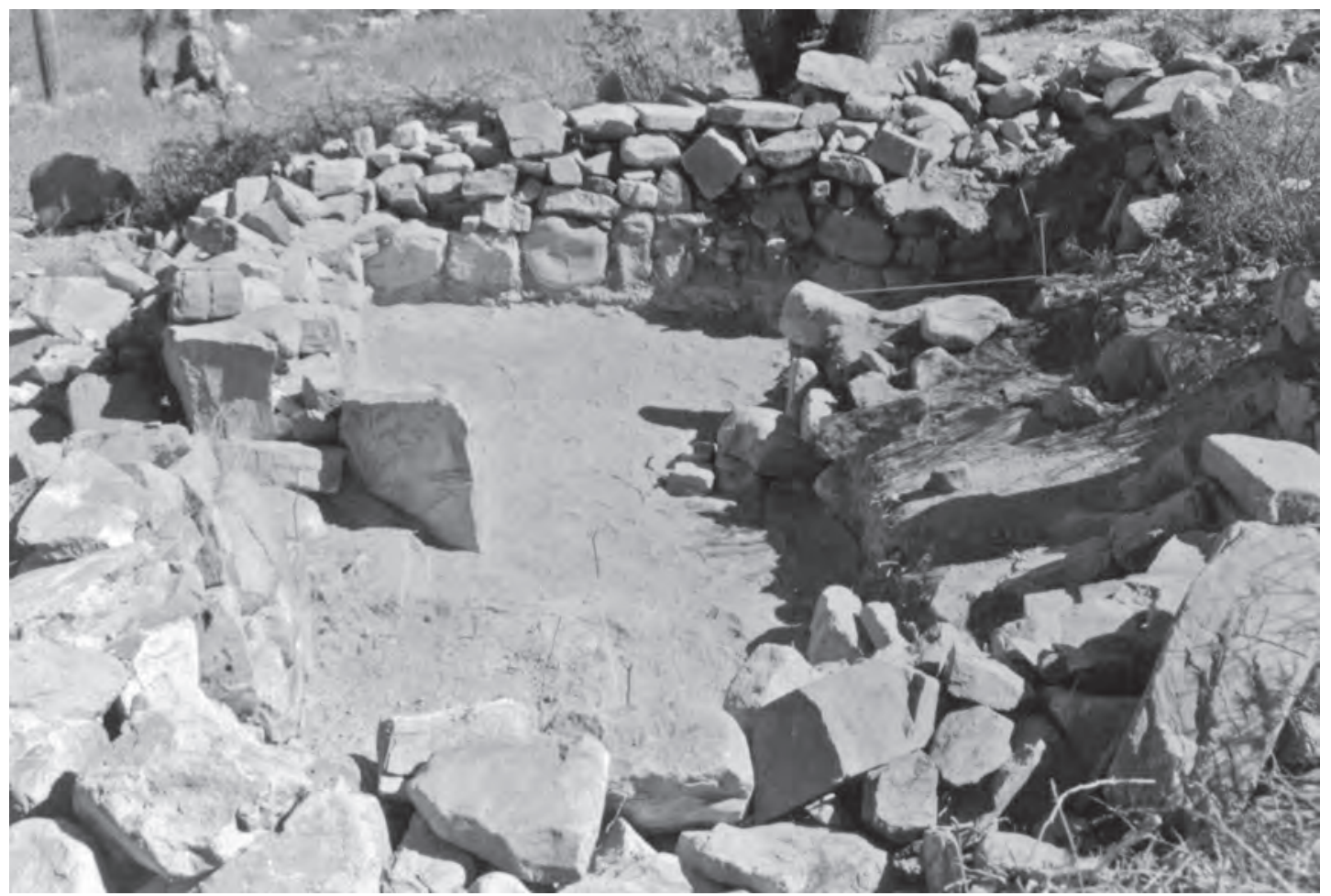

Figura 3: Recinto 353 


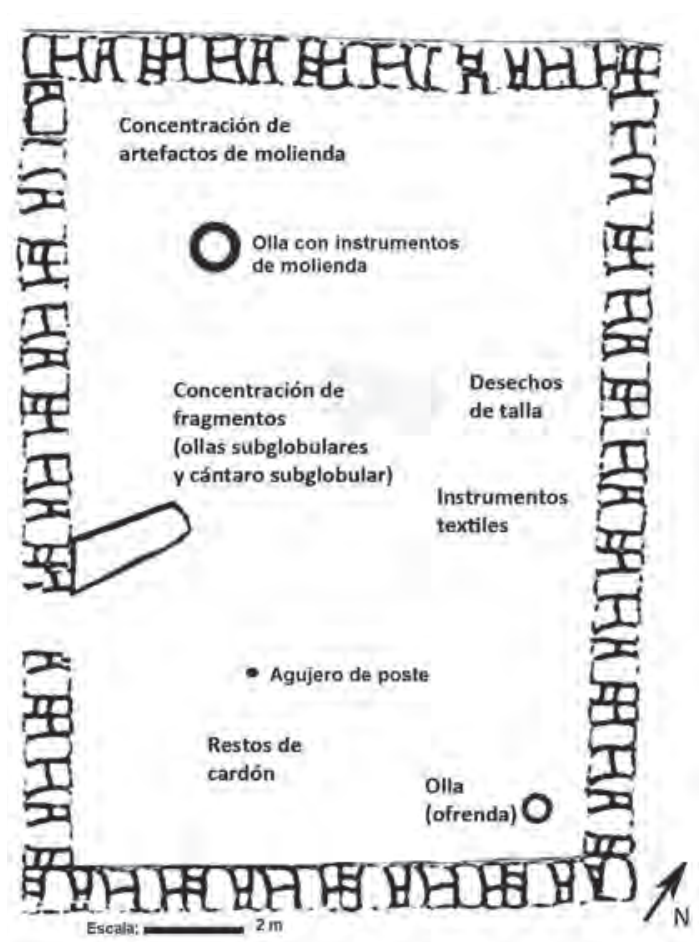

Figura 4: Distribución de evidencias arqueológicas en el recinto 353

Hacia el sector E del recinto se concentran algunos vestigios vinculados a la producción lítica y actividades textiles. Con respecto a la primera, se han hallado dos núcleos y cinco lascas de obsidiana y en relación a la segunda, un tortero y dos punzones óseos (Fig. 4).

Por otro lado, se registran en todo el recinto gran cantidad de restos de vasijas cerámicas tanto ordinarias como decoradas.

Entre las primeras pueden mencionarse cinco piezas halladas fragmentadas y que pudieron ser remontadas parcialmente. Se trata de cuatro ollas subglobulares (tres de las cuales presentan rastros de exposición al fuego) con una altura aproximada de entre 40 y $45 \mathrm{~cm}$ y un cántaro subglobular (Fig. 4). Entre los fragmentos cerámicos decorados se presentan los grupos habituales para el sitio y la Quebrada de Humahuaca en general: Rojizo Pulido, Gris Pulido, Altiplánico e Inca Provincial (Palma 1996). A partir de la identificación de partes diagnósticas y del remontaje parcial de algunas piezas se ha podido determinar la presencia una importante cantidad de escudillas rojizas pulidas, así como un plato y tres aribaloides Inca Provincial.

Respecto a la evidencia de alimentos, han sido recuperados restos de cáscara de huevo, una tusa y maní. El análisis de los restos faunísticos indica que se priorizó el taxón camelidae, especialmente individuos mayores de tres años, recuperándose los restos de cinco individuos. Las partes esqueletarias predominantes corresponden al esqueleto apendicular mientras que el esqueleto axial se encuentra escasamente representado, hecho observado en la ausencia de costillas y la baja proporción de vértebras. Una posible explicación para esta diferencia podría ser el consumo preferencial de las primeras, sin embargo, el hecho de que existan huellas de corte y fracturas intencionales en ambos esqueletos supone la idea de un aprovechamiento integral de los animales (Llago 2009).

El hallazgo de metal de adscripción hispana, una cuenta de vidrio y restos óseos del taxón ovicáprido (Llago 2009) indicarían una continuación en la utilización del recinto hasta momentos de contacto hispano-indígena. Esto resulta coherente con otros materiales similares recuperados en el sitio y con los fechados radiocarbónicos obtenidos para el recinto 293, los cuales indican una ocupación hasta el siglo XVI (Palma 2007).

Como antes se mencionó, si bien por su tamaño el recinto 353 debería incluirse entre los recintos del Estrato 2 (Raffino y Alvis 1993), la variedad y cantidad de vestigios recuperados relacionados con diferentes actividades y, particularmente, la ausencia de enterratorios y fogones, estarían indicando que no se trataría de un patio compartido por los miembros de un grupo doméstico en sus actividades cotidianas sino un espacio donde se desarrollaban múltiples actividades pero quizás a una escala de producción mayor que las necesidades propias de un grupo doméstico.

En este sentido, la evidencia más sustancial está constituida por los instrumentos de molienda, los restos faunísticos y los recipientes cerámicos vinculados a la preparación, almacenaje y servicio de alimentos y/o bebidas. Dada la au- 
sencia de fogones en el recinto, podría pensarse en un procesamiento y preparación inicial de determinados alimentos y su posterior cocción en otra área (quizás en el recinto contiguo 355, con el que tiene comunicación directa), para luego ser distribuidos y consumidos en otros sectores del sitio.

Como sostiene Hendon (1996), a pesar de la poca importancia que se le asigna a la preparación de alimentos, en algunos casos, esta cobra dimensión política debido a que esta actividad se vuelve crítica para cumplir con las obligaciones hacia la sociedad, a menudo bajo la forma de fiestas rituales o tributo dado a los líderes políticos.

En las sociedades andinas, la organización de festejos ceremoniales fue constante entre las elites, con su máxima sistematización en el estado Inca. En estos eventos, grandes cantidades de alimentos y bebidas eran ofrecidos a los participantes, renovándose los lazos de reciprocidad asimétrica entre gobernantes y gobernados (Tarragó et al 1998/99: 412).

Entonces, podría pensarse el recinto 353 como un espacio donde miembros de un mismo grupo doméstico o de diferentes grupos son reunidos allí para desarrollar determinadas actividades más allá de las necesidades de su propia unidad doméstica. Esto nos conduce a reflexionar sobre la concepción habitual de unidad doméstica, como espacio donde un grupo familiar realiza sus actividades cotidianas y la dicotomía espacio público/espacio doméstico.

De acuerdo con Moore (1996) la arquitectura pública refleja dimensiones más amplias del orden social. Para el autor, la arquitectura pública es un medio que contiene información sobre relaciones sociales asociadas con el poder (1996: 3). Así como los espacios públicos pueden constituirse en la evidencia material de relaciones sociales desiguales, el ejemplo del recinto 353 muestra que esto puede ocurrir también en otros espacios socialmente construidos. Este recinto podría considerarse como un espacio "intermedio" donde se desarrollan actividades de tipo doméstico pero cuya producción no se organiza en términos de los requerimientos de un grupo doméstico (como es el caso de los patios) sino en función de las necesidades impuestas por la sociedad mayor en la cual esos individuos se insertan, por ejemplo el consumo en fiestas y ceremonias públicas. Como indican Hastorf y Johannessen (1993) la preparación y consumo de alimentos en una sociedad se vincula a diferentes prácticas sociales y simbólicas y puede revelar cambios a nivel político e ideológico.

Teniendo en cuenta que el recinto se ubica en el sector incaico del sitio y la presencia de cerámica Inca Provincial podría pensarse en un espacio manejado por el estado donde se desarrollaban diversas actividades vinculadas a las necesidades estatales. Junto al procesamiento y/o preparación de alimentos como actividad principal desarrollada en el recinto, podría sumarse la producción lítica y la actividad textil (aunque la evidencia es más escasa).

En este sentido, consideramos que los espacios donde se desarrollan estas actividades, como el recinto 353, pueden ser vistos como medios para crear y reforzar relaciones hegemónicas con las poblaciones dominadas. La materialización de la ideología dominante en diferentes formas -entre ellas la arquitectura- fue uno de los medios principales a través de los cuales los incas negociaron relaciones políticas con los líderes locales, cuya autoridad pasó a depender de su vínculo con el estado (DeMarrais, Castillo y Earle 1996). Esto puede lograrse no sólo a partir de arquitectura pública de gran magnitud sino también en espacios pequeños donde la dominación se manifiesta tanto a través del espacio socialmente construido como a partir de la significación social de las actividades realizadas en ese espacio.

Un hallazgo excepcional realizado en el recinto, refuerza esta idea. Se trata de una olla de $26 \mathrm{~cm}$ de alto ubicada en la esquina SE del recinto, a $40 \mathrm{~cm}$ de profundidad, bajo el piso de ocupación (Fig. 5). Tiene forma subglobular, pertenece al grupo Ordinario y presenta rastros de exposición al fuego. Su boca estaba cubierta con una escudilla subhemisférica de interior gris pulido y todo, a su vez, tapado con un gran fragmento correspondiente a una olla que conservaba parte del borde y un asa. 


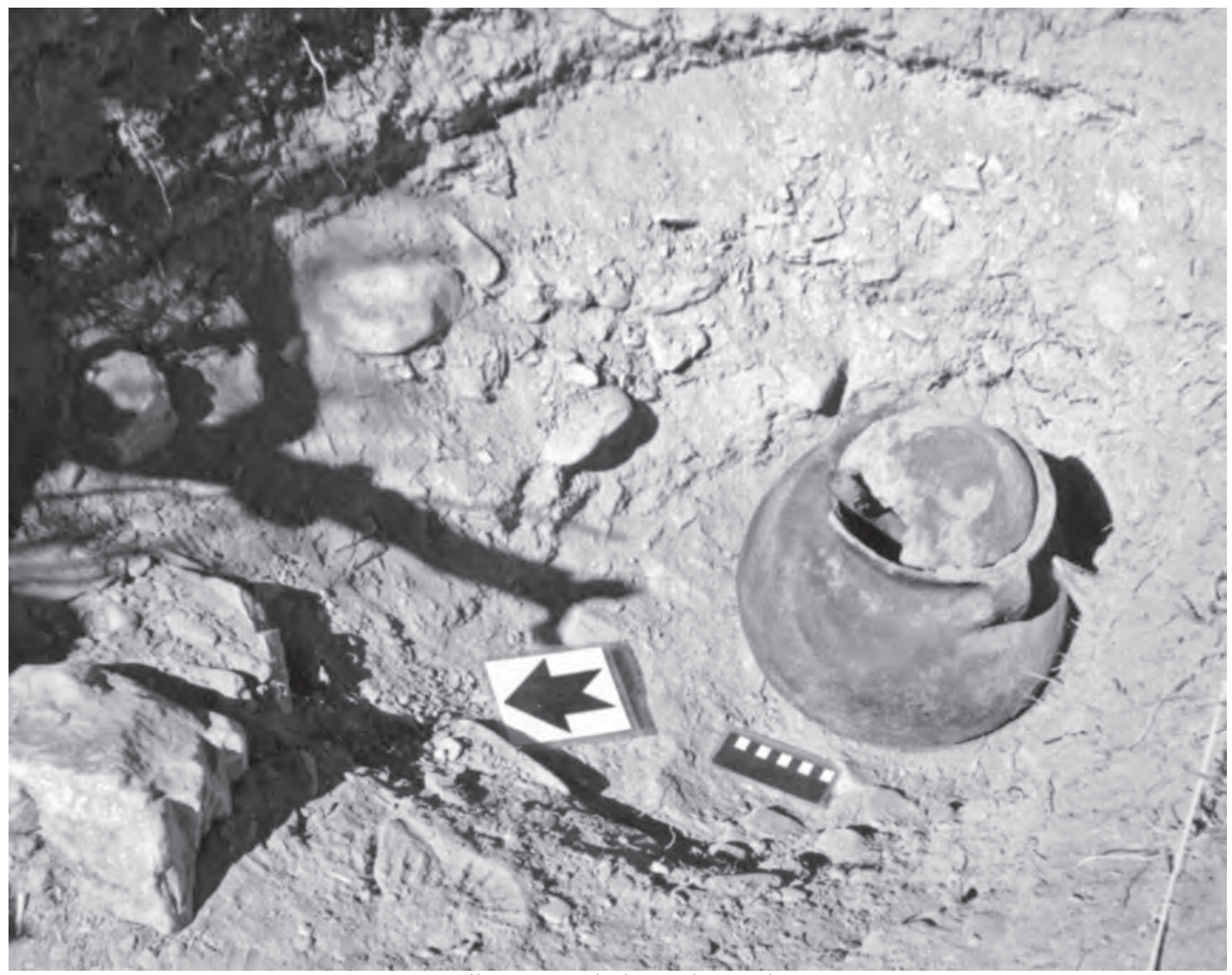

Figura 5: Olla enterrada bajo el piso de ocupación

En el interior de la olla estaban "guardados" varios instrumentos vinculados a la producción textil como un cuchillón de madera, cuyo mango apoyaba sobresaliendo en el borde de la olla, husos y torteros, ovillos e hilos, un peine utilizado para apretar la trama del tejido, dos bolsitas tejidas y fragmentos de textil. Sin embargo, también aparecen otros elementos entre los que se destacan: fragmentos de soga, tres tusas quemadas atadas con hilo, un anillo de bronce, un topo de plata doblado, una pinza de bronce y un cascabel de cáscara de nuez.

Dada su ubicación (debajo del piso de ocupación), el especial cuidado con el que parece haber sido acomodada y el hecho de estar "tapada" con un fragmento que la cubría completamente, podría pensarse que no se trataría de un recipiente que guarda objetos en su interior para ser usados habitualmente, sino una "ofrenda" enterrada intencionalmente. Considerando que los objetos de metal y los textiles son bienes muy preciados en el Tawantinsuyu, es significativa su presencia en una olla enterrada intencionalmente en un recinto donde probablemente se realizan actividades para el estado. Esto le otorga una significación especial no sólo a la olla en sí misma sino también al espacio donde se hallaba ubicada y a las actividades allí desarrolladas, configurándose como una metáfora (sensu Tilley 1999) de las nuevas relaciones socio-políticas establecidas por el estado.

\section{Palabras finales}

Habitualmente los enfoques que se centran en el espacio socialmente construido distinguen entre espacio público y espacio doméstico, donde en el primero se realizan actividades a gran 
escala que vinculan a toda o gran parte de la sociedad, mientras que en el segundo, las actividades se restringen a aquellas realizadas por el grupo doméstico.

En el caso del sitio La Huerta, la excavación y el análisis de las evidencias recuperadas en el recinto 353, nos permitieron reconocer un espacio donde se realizan actividades de tipo doméstico pero a una escala mayor que las necesidades de un grupo familiar, algunas de las cuales podrían vincularse a actividades públicas llevadas a cabo por el estado y realizadas en otros sectores del sitio.

Entonces, no sólo los espacios públicos y domésticos se constituyen como espacios que a través de la práctica reproducen los principios del orden social, sino que diferentes tipos de espacios socialmente construidos también pueden hacerlo.

Partiendo de una perspectiva más amplia que considera que la cultura material en general (arquitectura, utensilios, ropa, adornos, etc.) juega un rol activo en la conformación de prácticas sociales como medio de expresión de valores, categorías y significados culturales (Shanks y Tilley 1987, 1992; Appadurai 1991; Dant 1999), puede pensarse que los espacios, las actividades realizadas en los mismos y los objetos utilizados constituyen una forma de manifestar relaciones sociales, económicas y simbólicas y también, en algunos casos, una forma de materializar la dominación. De esta manera, en el caso del recinto analizado pensamos que se materializan las nuevas relaciones socio-políticas instauradas por el Tawantinsuyu.

\section{Agradecimientos}

A Patricia Pupkin, Gabriela Gastaldi, Roy Burke y a los alumnos del Seminario "Arqueología de campo" quienes participaron en la excavación del recinto y a Sofía Luco y Julia De Estéfano quienes colaboraron en el remontaje de las piezas cerámicas.

\section{Biblografía}

Appadurai, Ajurn (ed.)

1991 La vida social de las cosas. Perspectiva cultural de las mercancías. México D.F.: Grijalbo.

Criado Boado, Felipe

1993 "Límites y posibilidades de la arqueología del paisaje". SPAL. Revista de Prehistoria y Arqueología de la Universidad de Sevilla № 2: 9-55. Universidad de Sevilla.

Dant, Tim

1999 Material culture in the social world. Buckingham, Philadelphia: Open University Press.

Demarrais, Elisabeth, Luis J. Castillo y Timothy Earle

1996 "Ideology, materialization and power strategies". Current Anthropology 37(1): $15-31$.

Hastorf, Christine y Sissel Johannessen

1993 "Pre-Hispanic political change and the role of maize in the Central Andes of Peru". American Anthropologist Vol. 95, $\mathrm{N}^{\circ} 1: 115-138$

Hendon, Julia

1996 "Archaeological approaches to the organization of domestic labor: household practice and domestic relations". Annual Review of Anthropology 25: 45-61.

Ingold, Tim

1993 "The temporality of landscape". World Archaeology 25(2): 152-174.

Llago, María Alejandra

2009 "Análisis zooarqueológico del recinto 353 del sitio La Huerta, Huacalera". La Zaranda de Ideas. Revista de Jóvenes Investigadores en Arqueología 5: 185-193. Buenos Aires.

Moore, Jerry

1996 Architecture and power in the ancient Andes. The archaeology of public buildings. Cambridge: Cambridge University Press.

Nielsen, Axel

1996 "Demografía y cambio sociocultural en la Quebrada de Humahuaca”. Relaciones 
de la Sociedad Argentina de Antropología XXI: 307-385. Buenos Aires: Sociedad Argentina de Antropología.

2001 "Evolución social en Quebrada de Humahuaca (AD 700-1536)". En Historia argentina prehispánica Tomo I; Editores E. Berberián y A. Nielsen. Córdoba: Editorial Brujas.

2007 Celebrando con los antepasados. Arqueología del espacio público en Los Amarillos, Quebrada de Humahuaca, Jujuy, Argentina. Buenos Aires: Mallku Ediciones.

Palma, Jorge

1993 "Aproximación al estudio de una sociedad compleja: un análisis orientado en la funebria”. Arqueología. Revista de la Sección Arqueología. Instituto de Ciencias Antropológicas 3: 41-68. Facultad de Filosofía y Letras. Universidad de Buenos Aires.

1996 "Estructuras de descarte en un poblado prehispánico de la Quebrada de Humahuaca". Arqueología. Revista de la Sección Arqueología. Instituto de Ciencias Antropológicas 6: 47-67. Facultad de Filosofía y Letras. Universidad de Buenos Aires.

2000 "Urbanismo y complejidad social en la región Humahuaca". Estudios Sociales del NOA 4(3): 31-57. Instituto Interdisciplinario Tilcara. Facultad de Filosofía y Letras. Universidad de Buenos Aires.

2007 "Pre-Hispanic use of domestic space at La Huerta de Huacalera". Andean Past Vol. 8: 153-180.

Raffino, Rodolfo y Ricardo Alvis

1993 "Las 'ciudades' Inka en Argentina: arqueología de La Huerta de Humahuaca. El sistema de poblamiento prehispánico". En Raffino, R. (ed.) Inka. Arqueología, historia y urbanismo del Altiplano Andino; Buenos Aires: Editorial Corregidor.
Raffino, Rodolfo, Victoria García Montes y Alejandro Manso.

1993 'Las 'ciudades' Inka en Argentina: arqueología de La Huerta de Humahuaca. La funebria de La Huerta de Humahuaca”. En Raffino, R. (ed.) Inka. Arqueología, historia y urbanismo del Altiplano Andino; Buenos Aires: Editorial Corregidor.

Shanks, Michael y Christopher Tilley

1987 Social theory and archaeology. Cambridge: Polity Press.

1992 Re-constructing archaeology. Theory and practice. Londres: Routledge.

Tarragó, Miriam; Luis González; Paola Corvalán; Raúl Doro; Mariano Manasiewicz; Josefina Peña

1998/1999 "La producción especializada de alimentos en el asentamiento prehispánico de Rincón Chico, provincia de Catamarca". Cuadernos del Instituto Nacional de Antropología y Pensamiento Latinoamericano 18: 409-427. Buenos Aires: Instituto Nacional de Antropología y Pensamiento Latinoamericano.

Thomas, Julian

1996 Time, culture and identity. Londres: Routledge.

2001 "Archaeologies of place and landscapes". En Hodder, I. (ed.) Archaeological Theory Today; Cambridge: Polity Press.

Tilley, Christopher

1994 A phenomenology of landscape. Oxford: Berg.

1999 Metaphor and material culture. Oxford: Blackwell Publishers. 